\title{
Study on Acute Toxicity of Amiodarone New Complexes With Cyclodextrin
}

\section{OPEN ACCESS}

Edited by:

Sabina Passamonti,

University of Trieste, Italy

Reviewed by:

Adrian Nicolescu,

Queen's University, Canada

Sarasija Suresh

Institute for Drug Delivery and

Biomedical Research, India

Erem Bilensoy,

Hacettepe University, Turkey

*Correspondence:

Cristina Mihaela Ghiciuc

cristina.ghiciuc@umfiasi.ro

Andreea Creteanu

acreteanu@gmail.com

${ }^{+}$These authors have contributed equally to this work and share first authorship

Specialty section:

This article was submitted to Drug Metabolism and Transport, a section of the journal

Frontiers in Pharmacology

Received: 11 December 2020

Accepted: 17 February 2021

Published: 04 March 2021

Citation:

Ghiciuc CM, Shleghm MR, vasile C, Tantaru G, Creteanu A and Ochiuz L

(2021) Study on Acute Toxicity of

Amiodarone New Complexes With Cyclodextrin.

Front. Pharmacol. 12:640705.

doi: 10.3389/fphar.2021.640705
Cristina Mihaela Ghiciuc ${ }^{1 * t}$, Maytham Razaq Shleghm ${ }^{2 \dagger}$, Cornelia Vasile ${ }^{3}$, Gladiola Tantaru ${ }^{4}$, Andreea Creteanu ${ }^{5 *}$ and Lacramioara Ochiuz ${ }^{5}$

\begin{abstract}
${ }^{1}$ Department of Pharmacology, Faculty of Medicine, "Grigore T. Popa" University of Medicine and Pharmacy, lasi, Romania, ${ }^{2}$ Department of Applied Mathematics and Biostatistics, Faculty of Pharmacy, "Carol Davila" University of Medicine and Pharmacy, Bucharest, Romania, ${ }^{3}$ Physical Chemistry of Polymers Department, Petru Poni Institute of Macromolecular Chemistry, lasi, Romania, ${ }^{4}$ Department of Analytical Chemistry, Faculty of Pharmacy, "Grigore T. Popa" University of Medicine and Pharmacy, lasi, Romania, ${ }^{5}$ Department of Pharmaceutical Technology, Faculty of Pharmacy, "Grigore T. Popa" University of Medicine and Pharmacy, lasi, Romania
\end{abstract}

Amiodarone's low solubility and high permeability is the limiting step for its bioavailability, therefore new formulations are needed to improve the solubility of amiodarone either to increase its oral bioavailability or to reduce its toxic effects. Complexation of amiodarone with cyclodextrin results in an improved dissolution rate, solubility, and allows for a more controlled drug release. We characterized the acute toxicity of a new amiodarone 2hydroxypropyl- $\beta$-cyclodextrin complex (AMD/HP- $\beta-C D)$ in a powdered form and as a matrix based on Kollidon ${ }^{\circledR}$ and chitosan, administered intraperitoneally in laboratory animals. There were developed two formulations of matrix: one containing only pure $\mathrm{AMD}$ as a control sample $(\mathrm{Fc})$ and one containing the inclusion complex with the optimal solubility (F). AMD was equitoxic with HP- $\beta-C D$ after intraperitoneal administration $(289.4 \mathrm{mg} / \mathrm{kg}$ for $\mathrm{AMD}$ and $298.3 \mathrm{mg} / \mathrm{kg}$ for $A M D / H P-\beta-C D)$, with corresponding histopathological changes. The matrix based formulations presented higher LD50 values for acute toxicity, of $347.5 \mathrm{mg} / \mathrm{kg}$ for $\mathrm{FC}$ and $455.6 \mathrm{mg} / \mathrm{kg}$ for $\mathrm{F} 10$, leading to the idea of a safer administration because $\mathrm{KOL}$ and $\mathrm{CHT}$ matrix modified the solubility and controlled the AMD release. The LD50 value is 1.5 times higher for AMD/HP- $\beta-C D$ included in a $\mathrm{KOL}$ and $\mathrm{CHT}$ based matrix compared to the pure $\mathrm{AMD}$, administered intraperitoneally.

Keywords: amiodarone, cyclodextrin complex, acute toxicity, laboratory animals, new complexes

\section{INTRODUCTION}

Many generic formulations of Amiodarone hydrochloride (AMD) are available for the clinical practice, but there is a high inter-individual variability for AMD (Atanasova and Terziivanov, 2001). There is a need to develop and implement new delivery systems, which combines safety and efficacy, to improve the solubility of amiodarone either to increase its oral bioavailability or to reduce its toxic effects, or intended to shorten the onset of AMD action. AMD is a Class II drug (according to the Biopharmaceutical Classification System) because it has low solubility and high membrane permeability, therefore dissolution in gastrointestinal fluids is the limiting step for its oral bioavailability (Amidon et al., 1995; Benet, 2005). The solubility of a drug influence the choice of formulation for oral or parenteral administration, dissolution, and absorption from the digestive tube, therefore, development of new formulations with high solubility for low solubility compounds is a challenge. 
The hydroxypropyl- $\beta$-cyclodextrin $(\mathrm{HP}-\beta-\mathrm{CD})$ is a cyclodextrin with very good solubility and lowest toxicity, used to increase the solubility of various poorly soluble drugs (Gould and Scott, 2005; Jacob and Nair, 2018; Muankaew and Loftsson, 2018). Cyclodextrins (CD) are a family of cyclic oligosaccharides with a hydrophobic cavity containing the active compound which is internalized forming an inclusion complex with the drug. Complexation of a drug with cyclodextrins has numerous advantages such as an improved dissolution rate, improved bioavailability, safety, and stability and allows for a more controlled drug release (Szejtli, 2005; Tiwari et al., 2010). Thus, enhanced solubility and dissolution rate was obtained in vitro in the case of amiodarone complexation with $\beta$-cyclodextrin (Riekes et al., 2010). A recent in vitro study (Rubim et al., 2017) evaluated the influence of the $\mathrm{CD}$ type $(\beta$-cyclodextrin, methyl$\beta$-cyclodextrin, and 2-hydroxypropyl- $\beta$-cyclodextrin) on the complexation with $\mathrm{AMD}$ and on dissolution rate and found enhanced solubility and dissolution rates for inclusion complexes (Rubim et al., 2017). Only a few studies reported in vitro characterization of inclusion complexes of HP- $\beta-\mathrm{CD}$ with amiodarone (Rubim et al., 2017; Creteanu et al., 2019), but there is no data available about the acute toxicity of these systems.

Complexation of AMD with HP- $\beta-C D$ (AMD/HP- $\beta-C D$ ) increases its solubility and bioavailability without any modification of its structure (Păduraru et al., 2013; Creteanu et al., 2016a; Creţeanu et al., 2016b; Creteanu et al., 2017), therefore also the acute toxicity should increase. In one of our previous papers (Creteanu et al., 2019), the physicochemical properties have been evaluated for the inclusion complex formation with AMD and for two new formulations with a matrix based on Kollidon ${ }^{\circledR}$ (KOL) and chitosan (CHT), and it was established a considerably increase of the dissolution rate of AMD from the inclusion complexes, compared to dissolution of the pure AMD. The aim of this study was to evaluate the acute toxicity of AMD from new complexes with cyclodextrin AMD/HP- $\beta-C D$ as powdered form and as a matrix based $\mathrm{KOL}$ and $\mathrm{CHT}$, administered intraperitoneally in laboratory animals. There were developed two matrix based inclusion complex formulations: one containing only pure $\mathrm{AMD}$ as a control sample $(\mathrm{Fc})$ and one containing the inclusion complex with the optimal solubility (F10).

\section{MATERIALS AND METHODS}

\section{Materials}

Amiodarone $(\mathrm{AMD})(\mathrm{Mw}=645.32 \mathrm{Da})$ of $99.85 \%$ purity has been obtained from Zhejiang Sanmen Hengkang Pharmaceutical Co. Ltd., China. HP- $\beta$-CD of $99.70 \%$ purity has been obtained from Roquette, France. Polyoxyethylene (Hodge and Sterner, 1949) sorbitan monooleate (polysorbate 80, Tween 80) has been obtained from Sigma-Aldrich, Inc. Kollidon ${ }^{\circledR}$ SR (KOL), a mixture constituted from $80 \%$ poly(vinyl acetate) and $20 \%$ polyvinylpyrrolidone (povidone), and chitosan (CHT) were purchased from BASF, Germany.

AMD/HP- $\beta-C D$ contains AMD:cyclodextrin in a ratio $1: 1$. The substances were administered in constant volume $(0.1 \mathrm{ml} /$ $10 \mathrm{~g}$ b.w.) as freshly prepared suspension with distilled water and $1 \%$ Tween-80. The solutions for acute toxicity study were prepared using the same weight of powder of AMD, respectively of $\mathrm{AMD} / \mathrm{HP}-\beta-\mathrm{CD}, \mathrm{Fc}$ and F10 powders.

\section{Experimental Animals}

The protocol of the experimental study was approved by the Institutional Ethics Committee of "Grigore T. Popa" University of Medicine and Pharmacy of Iasi, Romania (No. 23983/2014). Healthy nulliparous and non-pregnant female Balb/C mice (weighting 20-25 g) were purchased from Cantacuzino Institute (Bucharest, Romania). The animal study was done in accordance with the international guidelines (National Research Council US Committee for the Update of the Guide for the Care and Use of Laboratory Animals, 2011). The animals were housed in plastic cages with stainless steel mesh lids in a ventilated room with standard environmental conditions: $12 \mathrm{~h}$ light-dark cycle, room temperature $24 \pm 2^{\circ} \mathrm{C}$ and $50-70 \%$ relative humidity. They were provided ad libitum with standard rodent pellet food and tap water, for 5 days before testing.

\section{Acute Toxicity Testing}

To obtain the $50 \%$ lethal dose (LD50) of the AMD, respectively $\mathrm{AMD} / \mathrm{HP}-\beta-\mathrm{CD}$, the experiments were designed in accordance with the "Up and Down Procedure" (UDP) provided by the Organization for Economic Cooperation and Development (OECD) Guideline 425 (OECD, 2008) and described by Dixon (Dixon, 1965). Limit test was performed at $2,000 \mathrm{mg} / \mathrm{kg}$ p.o. as single dose administered according to body weight. Main test was performed with doses adjusted by a constant multiplicative factor (namely 1.6) for this experiment: 175, 275, 440, 690 and $1,090 \mathrm{mg} / \mathrm{kg}$ b.w. The animals were fasted for $12 \mathrm{~h}$ prior to dosing and the single dose for each successive animal was adjusted up or down depending on the previous outcome, after $24 \mathrm{~h}$ one by one. Animals were closely observed during the first $30 \mathrm{~min}$, then hourly for the next $6 \mathrm{~h}$, at $24 \mathrm{~h}$ and daily for the next 14 days to record mortality and all the relevant clinical symptoms of acute toxicity (evaluation of skin and fur, grooming, posture and gait, salivation, tremor, convulsion, hyperactivity, apathy, respiratory depression, and coma). The LD50 is calculated using the maximum likelihood method with a sigma of 0.5 (OECD, 2008).

\section{Histopathological Study}

The vital organs (liver, kidney, lungs and heart) isolated from the dead mice were preserved in $10 \%$ formalin, then embedded in paraffin wax. Paraffin sections $(5 \mathrm{~mm})$ were stained with hematoxylin and eosin (HE) to be studied under a light microscope for morphological alterations.

\section{RESULTS}

\section{Acute Toxicity of AMD, of AMD/HP- $\beta-C D$, of AMD Control Matrix (FC), and of AMD/ HP- $\beta$-CD Fatrix (F) \\ Vital Signs}

During the entire study period, no unusual clinical signs were observed in the mice that received $175 \mathrm{mg} / \mathrm{kg}$ b.w of AMD, 

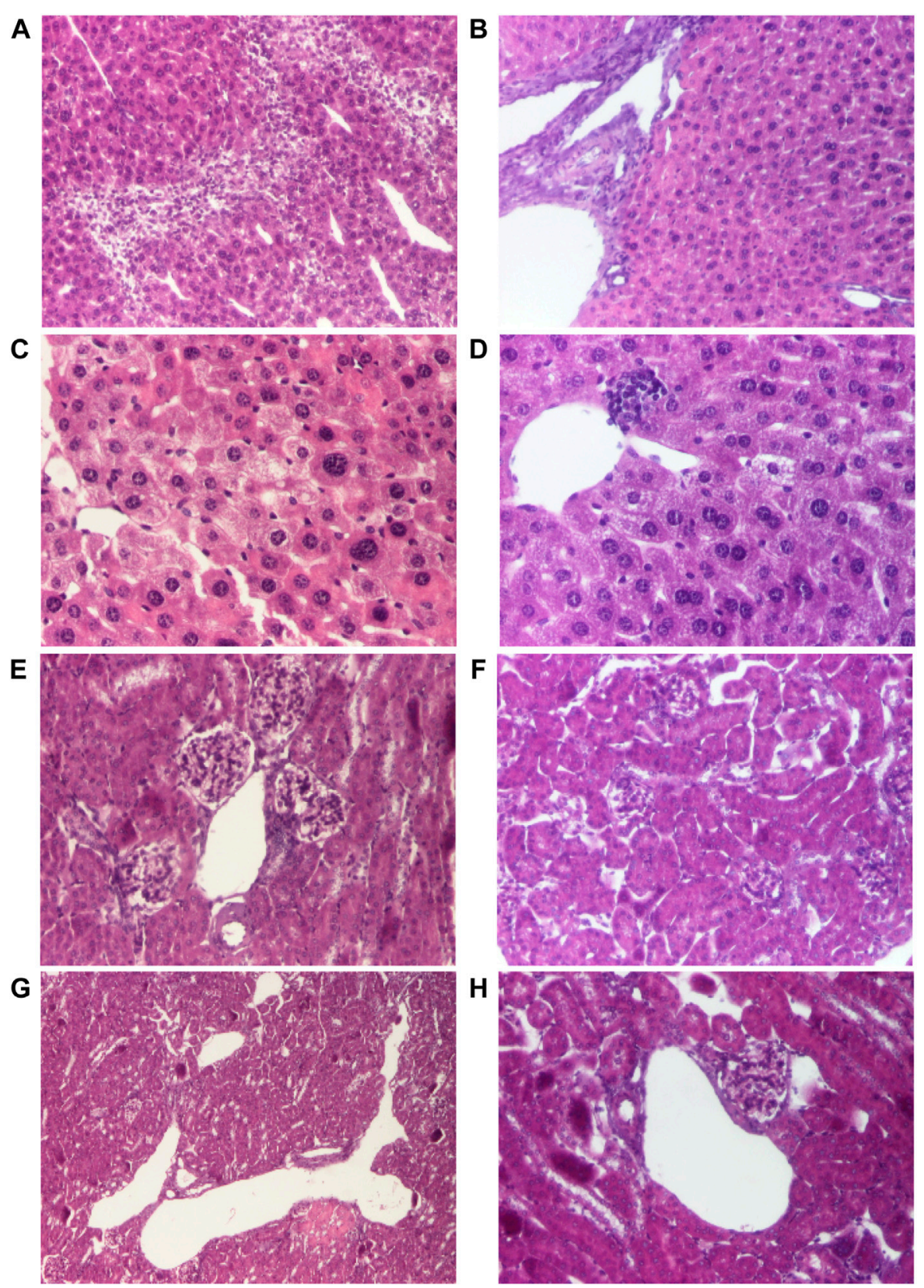

FIGURE 1| Histological changes of the main organs in the dead mice after doses of $690 \mathrm{mg} / \mathrm{kg}$ of AMD (A, C, E, G) compared to $440 \mathrm{mg} / \mathrm{kg}$ of AMD (B, D, F, H). Representative pictures from HE staining sections of the liver with hepatitis aspect (hematoxylin-eosin HE stain, $\times 100$ ) (A), liver-portal space (hematoxylin-eosin HE stain, $\times 100)(\mathbf{B})$, degeneration of hepatocytes (hematoxylin-eosin HE stain, $\times 200$ ) (D), hepatocytes (hematoxylin-eosin HE stain, $\times 200)(\mathbf{D})$, renal cortex and arteriole (hematoxylin-eosin HE stain, $\times 200$ ) (E), renal cortex (hematoxylin-eosin HE stain, $\times 100)(\mathbf{F})$, renal cortex and dilated renal veins (hematoxylin-eosin HE stain, $\times 40$ ) (G), renal cortex and dilated renal veins (hematoxylin-eosin HE stain, $\times 100)(\mathbf{H})$.

respectively AMD/HP- $\beta-\mathrm{CD}, \mathrm{Fc}$, and F. Supplementary Table S1 summarizes some behavioral responses of mice from the first $30 \mathrm{~min}$ and hourly during the first $6 \mathrm{~h}$ after administration of a single dose of administered substances. A decrease in sensitivity and activity, tremor and convulsions were observed at $690 \mathrm{mg} / \mathrm{kg}$ b.w., during the first hour, followed by death in the case of AMD, respectively AMD/HP- $\beta$-CD. A few animals (3 out of 4) showed slight symptoms after the dose of
$275 \mathrm{mg} / \mathrm{kg}$ for AMD/HP- $\beta-\mathrm{CD}$ and died $6 \mathrm{~h}$ after the administration of the substance. For matrix based inclusion complexes, a decrease in sensitivity and activity, tremor and convulsions were observed at $1,090 \mathrm{mg} / \mathrm{kg}$ b.w., during the first hour, followed by death for Fc and F10.

LD50 values of AMD, respectively AMD/HP- $\beta-C D$, using up and down procedure were determined to be $289.4 \mathrm{mg} / \mathrm{kg}$ for $\mathrm{AMD}$ and $298.3 \mathrm{mg} / \mathrm{kg}$ for AMD/HP- $\beta-\mathrm{CD}$. For the matrix based 

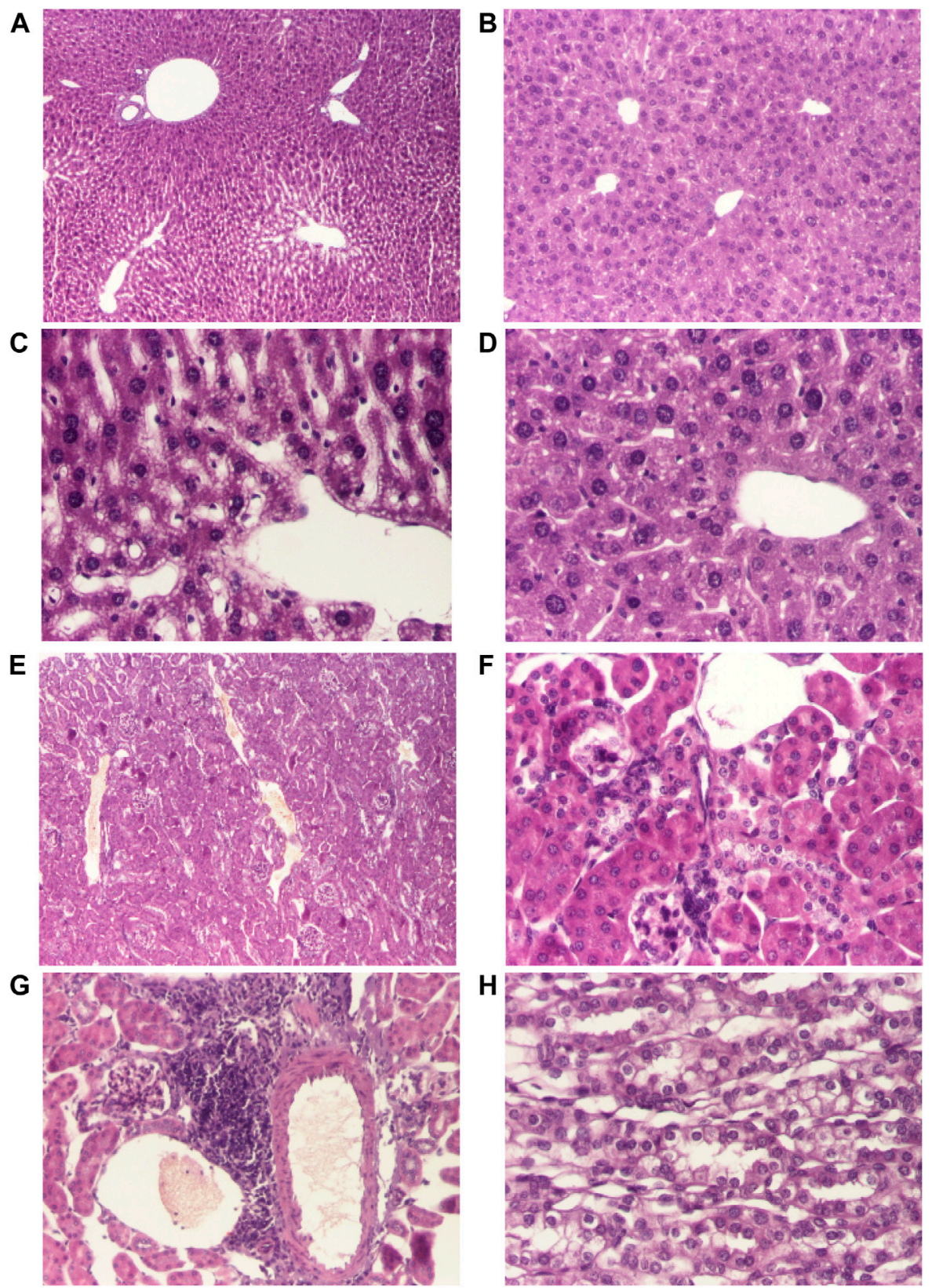

FIGURE 2 | Histological changes of the main organs in the dead mice after doses of $690 \mathrm{mg} / \mathrm{kg}$ of AMD/HP- $\beta-C D$ (A, C, E, G) compared to $440 \mathrm{mg} / \mathrm{kg}$ of AMD/ $\mathrm{HP}-\beta-\mathrm{CD}$ (B, D, F, H). Representative pictures from HE staining sections of the liver (hematoxylin-eosin HE stain, $x$ 40) (A, B), hepatocytes (hematoxylin-eosin HE stain, $\times 200)(\mathbf{C}, \mathbf{D})$, renal cortex (hematoxylin-eosin HE stain, $\times 40)(\mathbf{E})$, renal cortex (hematoxylin-eosin HE stain, $\times 100)(\mathbf{F})$, interstitial nephritis (hematoxylin-eosin HE stain, $\times 100)(\mathbf{G})$, renal medulla (hematoxylin-eosin HE stain, $\times 200$ ) (H).

formulations, LD50 values were $347.5 \mathrm{mg} / \mathrm{kg}$ for $\mathrm{Fc}$ and $455.6 \mathrm{mg} / \mathrm{kg}$ for F10.

\section{Histopathological Evaluation}

Necropsy was carried out in all animals immediately after death. Internal organs (liver, kidney, lungs and heart) were examined for macroscopic alterations induced by $\mathrm{AMD}$, respectively $\mathrm{AMD} / \mathrm{HP}-\beta-\mathrm{CD}$, and collected to perform histopathological analysis (Figures 1, 2). No macroscopic changes were observed.

Histopathological examination of liver and kidney fragments in animals which received toxic doses of $690 \mathrm{mg} / \mathrm{kg}$ of AMD revealed suggestive aspects of drug-induced hepatotoxicity (Figures 1A,C), compared to doses of $440 \mathrm{mg} / \mathrm{kg}$ of AMD 

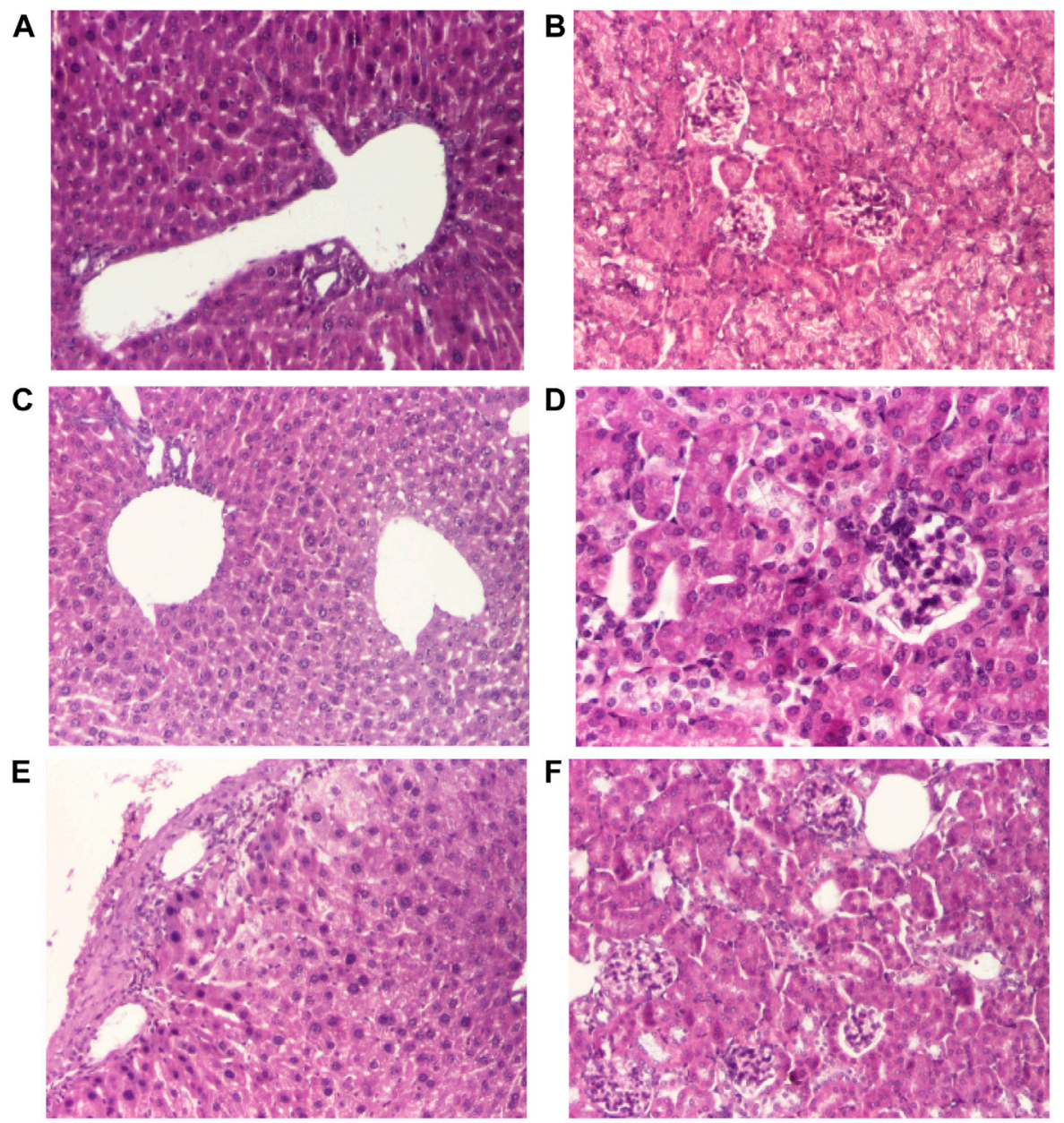

FIGURE 3 | Histological changes of the main organs in the dead mice after doses of $690 \mathrm{mg} / \mathrm{kg}$ of FC (A, B) and F10 (C, D) and after doses of 1,090 mg/kg of F10 (E, F). Representative pictures from HE staining sections of the liver (hematoxylin-eosin HE stain, $\times 100)(\mathbf{A}, \mathbf{C}, \mathbf{E})$, renal (hematoxylin-eosin HE stain, $\times 100)(\mathbf{C}, \mathbf{D}, \mathbf{F})$.

(Figures 1B,D). In the kidney, there are typical changes induced by $690 \mathrm{mg} / \mathrm{kg}$ of AMD (Figures 1E,G) compared to doses of $440 \mathrm{mg} / \mathrm{kg}$ of AMD (Figures 1F,H).

Histopathological examination of liver fragments in animals which received toxic doses of $690 \mathrm{mg} / \mathrm{kg}$ of $\mathrm{AMD} / \mathrm{HP}-\beta-\mathrm{CD}$ revealed suggestive aspects of drug-induced hepatotoxicity (Figures 2A,C), compared to doses of $440 \mathrm{mg} / \mathrm{kg}$ of AMD/ HP- $\beta$-CD (Figures 2B,D). Histopathological examination at the renal level revealed a few changes characteristic of nephrotoxicity induced by $690 \mathrm{mg} / \mathrm{kg}$ of $\mathrm{AMD} / \mathrm{HP}-\beta-\mathrm{CD}$ (Figures 2E,G) and by $440 \mathrm{mg} / \mathrm{kg}$ of AMD/HP- $\beta-\mathrm{CD}$ (Figures 2F,H.).

Histopathological examination of liver and kidney fragments in animals which received toxic doses of $690 \mathrm{mg} / \mathrm{kg}$ of $\mathrm{Fc}$ (Figures 3A,B) and F10 (Figures 3C,D) revealed a few changes characteristic of hepatic and nephrotoxicity. They were analyzed only for the doses of $1,090 \mathrm{mg} / \mathrm{kg}$ for F10 which revealed signs of hepatic and nephrotoxicity (Figures 3E,F).

\section{DISCUSSION}

Our study found that AMD/HP- $\beta-\mathrm{CD}$ has similar acute toxicity with pure AMD after oral administration in mice: $289.4 \mathrm{mg} / \mathrm{kg}$ for AMD and $298.3 \mathrm{mg} / \mathrm{kg}$ for AMD/HP- $\beta$-CD. Similar doses of these compounds produced equivalent degree of acute toxicity only for AMD, respectively AMD/HP- $\beta-C D$. For the matrix based formulations, LD50 values were $347.5 \mathrm{mg} / \mathrm{kg}$ for $\mathrm{Fc}$ and $455.6 \mathrm{mg} / \mathrm{kg}$ for F10. The KOL and CHT matrix induced high differences in the solubility and controlled AMD release: The LD50 is 1.5 times higher when AMD is complexed with HP- $\beta-C D$ and included in F10 matrix than for pure AMD. These formulations are considered moderately toxic (dose between $50-500 \mathrm{mg} / \mathrm{kg}$ ), according to Hodge and Sterner scale for the evaluation of toxicity with the help of LD50 (Hodge and Sterner, 1949), with F10 being closer to the limit of slightly toxic. Amiodarone is difficult to administer because of its narrow toxic-therapeutic range (Tamargo et al., 2015). In our study, intraperitoneal administration of AMD had comparable results to 
other acute toxicity studies with Amiodarone: LD50 of $294.0 \mathrm{mg} / \mathrm{kg}$ body weight in female mice after intravenous administration (Barle et al., 2013). The matrix based formulation increased the solubility and modified the release of the substance from the formulation.

Hydroxypropyl- $\beta$-Cyclodextrin (HP- $\beta-\mathrm{CD})$ is highly biocompatible and pharmacologically inactive, therefore it was considered a safe material to improve the solubility and the bioavailability of AMD (Patel and Hirlekar, 2019). A cyclodextrin-complex formulation containing a well-known long used drug is considered a "super generic", superior in its performance when compared to other products which contain the same known active substance (Szejtli, 2005). In the case of oral administration, pharmacokinetic studies showed that drug/ cyclodextrin complexes have shorter Tmax, higher Cmax and larger AUC values as a result of the increased bioavailability (Szejtli, 2005). Pharmacodynamic studies showed that most drug/ cyclodextrin complexes from the market belong to these super generic drugs having a higher and quicker therapeutic effect (Szejtli, 2005). A recent pharmacokinetic study conducted in rats after intravenous bolus administration showed that the inclusion of HP- $\beta$-CD in the solution of the administered substance improved blood compatibility (Mantik et al., 2019). Polysorbate 80 (Tween 80 ), a nonionic surfactant, is considered non-toxic, being used as an additive, as emulsifier, as dispersant, or as stabilizer in various type of foods, pharmaceutical preparations, or cosmetics (National Toxicology Program, 1992; EFSA FEEDAP Panel, 2016).

On the other hand, Amiodarone has a narrow therapeutic ratio and it is considered a critical dose drug, therefore, increasing the solubility and the controlled AMD release to reduce the active drug dose in the new super generic cyclodextrin formulation was considered an obvious idea. In our experiment, LD50, based on up and down procedure, was $289.4 \mathrm{mg} / \mathrm{kg}$ for $\mathrm{AMD}$, similar to LD50 values from literature (Barle et al., 2013) and $298.3 \mathrm{mg} / \mathrm{kg}$ for the new inclusion cyclodextrine complex HP- $\beta-C D$, meaning that AMD and its complex, HP- $\beta-C D$, had equivalent degree of toxicity. Single dose administration of $440 \mathrm{mg} / \mathrm{kg}$ and of $690 \mathrm{mg} / \mathrm{kg}$ of the classical AMD or of our new formulation HP- $\beta-C D$ produced equivalent toxic effects in mice: both caused complex symptoms such as changes in breathing, agitation, increased heart rhythm, convulsions, tremors, cyanosis, falls, defecation, urination, and piloerection. In mice, both $\mathrm{AMD}$ and $\mathrm{HP}-\beta-\mathrm{CD}$, and matrix formulations determined hepatic and renal toxicity lesions, similar to those reported in the literature after high doses of AMD. These effects were not seen in matrix formulations Fc and F10. In humans, AMD-induced acute toxicity syndrome is unusual, manifested with acute liver and renal failure (Paudel et al., 2016). Central nervous system manifestations were described in the literature when toxic doses of AMD were administered. In the literature, cases of pulmonary damage, e.g., acute pulmonary edema, have been reported following administration of toxic doses of AMD in humans (Kaya et al., 2017).

\section{CONCLUSION}

Our single dose acute toxicity study showed that the same amount of AMD was equitoxic with HP- $\beta-C D$, after intraperitoneal administration, the lethal doses (DL50) of these pharmaceutical forms included them into the category 3 of toxicity (moderately toxic substances). For the matrix based formulations, LD50 values were higher pointing to the idea of a safer administration because KOL and CHT matrix induced high differences in the solubility and controlled AMD release. The LD50 value is 1.5 times higher for AMD/HP- $\beta$-CD included in a $\mathrm{KOL}$ and CHT based matrix compared to the pure AMD, administered using the same route.

\section{DATA AVAILABILITY STATEMENT}

The original contributions presented in the study are included in the article/Supplementary Material, further inquiries can be directed to the corresponding authors.

\section{ETHICS STATEMENT}

The animal study was reviewed and approved by the Ethics Committee of "Grigore T. Popa" University of Medicine and Pharmacy of Iasi, Romania (No. 23983/2014). Written informed consent was obtained from the owners for the participation of their animals in this study.

\section{AUTHOR CONTRIBUTIONS}

Conceptualization: CG, MS, and LO. Writing-original draft preparation: CG, MS, AC, and GT. Writing-review and editing: CG, MS, CV, AC, and LO. Visualization: CG, MS, and GT. Supervision: $\mathrm{CV}$ and LO. Funding acquisition: GT. All authors contributed to the article and approved the submitted version.

\section{FUNDING}

The work was partially supported by personal funds. The formulations leading to these results have received funding from Grigore T. Popa - Iasi through the project 29025/2016.

\section{SUPPLEMENTARY MATERIAL}

The Supplementary Material for this article can be found online at: https://www.frontiersin.org/articles/10.3389/fphar.2021.640705/ full\#supplementary-material. 


\section{REFERENCES}

Amidon, G. L., Lennernäs, H., Shah, V. P., and Crison, J. R. (1995). A theoretical basis for a biopharmaceutic drug classification: the correlation of in vitro drug product dissolution and in vivo bioavailability. Pharm. Res. 12 (3), 413-420. doi:10.1023/a:1016212804288

Atanasova, I., and Terziivanov, D. (2001). Evaluation of average bioequivalence of two oral formulations of amiodarone hydrochloride after single administration to healthy volunteers. Clin. Drug Investig. 21, 423-428. doi:10.2165/00044011-200121060-00005

Barle, E. L., Černe, M., Peternel, L., and Homar, M. (2013). Reduced intravenous toxicity of amiodarone nanosuspension in mice and rats. Drug Chem. Toxicol. 36 (3), 263-269. doi:10.3109/01480545.2012.710628

Benet, L. Z. (2005). There are no useful CYP3A probes that quantitatively predict the in vivo kinetics of other CYP3A substrates and no expectation that one will be found. Mol. Interv. 5 (2), 79-83. doi:10.1124/mi.5.2.5

Creteanu, A., Ochiuz, L., Vasile, C., Paduraru, O. M., Popescu, M.-C., Vieru, M., et al. (2016a). Thermal stability assesment OF amiodarone hydrochloride IN polymeric matrix tablets. Farmacia 64 (6), 940-945.

Crețeanu, A., Ochiuz, L., Vieriu, M., Panainte, A. D., and Țântaru, G. (2016b). In Vitro dissolution studies of amiodarone hydrochloride from hydroxypropyl- $\beta$-cyclodextrin/amiodarone inclusion complex formulated into modified-release tablets. Rev. Med. Chir. Soc. Med. Nat. Iasi 120 (3), 715-719.

Creteanu, A., Ochiuz, L., Vasile, C., Vieru, M., and Ţântaru, G. (2017). Studies on the influence of amiodarone complexation with cyclodextrin derivatives $\mathrm{ON}$ the In Vitro release from matrix tablets. Farmacia 65(4), 545-549.

Creteanu, A., Pamfil, D., Vasile, C., Tantaru, G., Ghiciuc, C. M., Ochiuz, L., et al. (2019). Study on the role of the inclusion complexes with 2-Hydroxypropyl$\beta$-cyclodextrin for oral administration of amiodarone. Int. J. Polym. Sci. 2019, 1-23. doi:10.1155/2019/1695189

Dixon, W. J. (1965). The up-and-down method for small samples. J. Am. Stat. Assoc. 60 (312), 967-978. doi:10.1080/01621459.1965.10480843

EFSA FEEDAP Panel (2016). EFSA Panel on Additives and Products or Substances used, in Animal Feed). Safety and efficacy of polyoxyethylene (20) sorbitan monooleate as a feed additive for all animal species. EFSA J. 14 (3), 4443-4461. doi:10.2903/j.efsa.2016.4443

Gould, S., and Scott, R. C. (2005). 2-Hydroxypropyl- $\beta$-cyclodextrin (HP- $\beta$-CD): a toxicology review. Food Chem. Toxicol. 43 (10), 1451-1459. doi:10.1016/j.fct. 2005.03.007

Hodge, H. C., and Sterner, J. H. (1949). Tabulation of toxicity classes. Am. Ind. Hyg. Assoc. Q. 10 (4), 93-96. doi:10.1080/00968204909344159

Jacob, S., and Nair, A. B. (2018). Cyclodextrin complexes: perspective from drug delivery and formulation. Drug Dev. Res. 79 (5), 201-217. doi:10.1002/ddr. 21452

Kaya, S. B., Deger, S., Hacievliyagil, S. S., and Aytemur, Z. A. (2017). Acute amiodarone toxicity causing respiratory failure. Rev. Assoc. Med. Bras. 63 (3), 210-212. doi:10.1590/1806-9282.63.03.210

Mantik, P., Xie, M., Wong, H., La, H., Steigerwalt, R. W., Devanaboyina, U., et al. (2019). Cyclodextrin reduces intravenous toxicity of a model compound. J. Pharm. Sci. 108 (6), 1934-1943. doi:10.1016/j.xphs.2019. 01.004
Muankaew, C., and Loftsson, T. (2018). Cyclodextrin-based formulations: a noninvasive platform for targeted drug delivery. Basic Clin. Pharmacol. Toxicol. 122 (1), 46-55. doi:10.1111/bcpt.12917

National Research Council US Committee for the Update of the Guide for the Care and Use of Laboratory Animals (2011). Guide for the care and use of laboratory animals. 8th Edn. Washington, DC: National Academies Press (US). . Available at: http://www.ncbi.nlm.nih.gov/books/NBK54050/ (Accessed February 3, 2021).

National Toxicology Program (1992). NTP toxicology and carcinogenesis studies of polysorbate 80 (CAS No. 9005-65-6) in F344/N rats and B6C3F1 mice (feed studies). Natl. Toxicol. Program Tech. Rep. Ser. 415, 1-225.

OECD (2008). Test No. 425: acute oral toxicity: up-and-down procedure. Available at: https://www.oecd-ilibrary.org/content/publication/9789264071049-en. (Accessed February, 2021)

Patel, M., and Hirlekar, R. (2019). Multicomponent cyclodextrin system for improvement of solubility and dissolution rate of poorly water soluble drug. Asian J. Pharm. Sci. 14 (1), 104-115. doi:10.1016/j.ajps.2018.02.007

Paudel, R., Dogra, P., Suman, S., Acharya, S., and Matta, J. (2016). Acute liver and renal failure: a rare adverse effect exclusive to intravenous form of amiodarone. Case Rep. Crit. Care 2016, 5232804. doi:10.1155/2016/5232804

Păduraru, O. M., Bosînceanu, A., Ţântaru, G., and Vasile, C. (2013). Effect of hydroxypropyl- $\beta$-cyclodextrin on the solubility of an antiarrhythmic agent. Ind. Eng. Chem. Res. 52 (5), 2174-2181. doi:10.1021/ie303440w

Riekes, M. K., Tagliari, M. P., Granada, A., Kuminek, G., Silva, M. A. S., and Stulzer, H. K. (2010). Enhanced solubility and dissolution rate of amiodarone by complexation with $\beta$-cyclodextrin through different methods. Mater. Sci. Eng. C 30 (7), 1008-1013. doi:10.1016/j.msec.2010.05.001

Rubim, A. M., Rubenick, J. B., Maurer, M., Laporta, L. V., Rolim, C. M. B., Rubim, A. M., et al. (2017). Inclusion complex of amiodarone hydrochloride with cyclodextrins: preparation, characterization and dissolution rate evaluation. Braz. J. Pharm. Sci. 53 (2). doi:10.1590/s2175-97902017000216083

Szejtli, J. (2005). Cyclodextrin complexed generic drugs are generally not bioequivalent with the reference products: therefore the increase in number of marketed drug/cyclodextrin formulations is so slow. J. Incl. Phenom. Macrocycl. Chem. 52 (1), 1-11. doi:10.1007/s10847-004-7161-z

Tamargo, J., Le Heuzey, J.-Y., and Mabo, P. (2015). Narrow therapeutic index drugs: a clinical pharmacological consideration to flecainide. Eur. J. Clin. Pharmacol. 71 (5), 549-567. doi:10.1007/s00228-015-1832-0

Tiwari, G., Tiwari, R., and Rai, A. (2010). Cyclodextrins in delivery systems: Applications. J. Pharm. Bioall. Sci. 2 (2), 72-79. doi:10.4103/0975-7406.67003

Conflict of Interest: The authors declare that the research was conducted in the absence of any commercial or financial relationships that could be construed as a potential conflict of interest.

Copyright $\odot 2021$ Ghiciuc, Shleghm, Vasile, Tantaru, Creteanu and Ochiuz. This is an open-access article distributed under the terms of the Creative Commons Attribution License (CC BY). The use, distribution or reproduction in other forums is permitted, provided the original author(s) and the copyright owner(s) are credited and that the original publication in this journal is cited, in accordance with accepted academic practice. No use, distribution or reproduction is permitted which does not comply with these terms. 